\title{
Long survival in subacute sclerosing panencephalitis
}

\author{
WA COBB, JOHN MARSHALL AND F SCARAVILLI \\ From the Institute of Neurology, National Hospitals for Nervous Diseases' Queen Square, London, UK
}

SUMMARY A case is reported of a boy who at the age of 14 years developed subacute sclerosing panencephalitis. He deteriorated over a period of 9 months, improved greatly and remained stable for 7 years before relapse. The final deterioration to death extended over 6 years. During the whole period he was examined regularly and the electroencephalogram recorded at 3 to 6 monthly intervals. The brain was examined histologically after death. Electroencephalographic and pathological features are described.

Subacute sclerosing panencephalitis (SSPE) is usually fatal within months. However reports of long survival and apparent remission have appeared..$^{1-17}$ In some, doubt may be cast on the diagnosis ${ }^{9}$ but in others, including a necropsy series of 50 cases with two survivals of four and five years respectively ${ }^{7}$ the diagnosis was beyond doubt. The literature has recently been thoroughly reviewed. ${ }^{18}$

Epidemiological surveys and the establishment of SSPE registers have indicated that remission and long survival may not be as unusual as was previously thought. ${ }^{19-23}$ It has been reported that $50 \%$ of cases may cease to deteriorate for a time or may experience notable improvement and that $20 \%$ may survive for four or more years. ${ }^{22}$ However detailed clinical and electrophysiological information was not always available throughout. The present case is reported because throughout the 14 years of his illness he was examined at regular intervals by one of us (JM), the EEG was recorded on 36 occasions (WAC) and finally the brain was examined histologically (FS).

\section{Case report}

The patient presented to us at the age of 14 years with an 8 month history of deterioration in his school-work and attacks. Between the ages of 2 and 5 years he had mumps, chicken pox and measles. In March 1968 a slight falling off in his school-work was noted and in April attacks in which he would stare ahead for 10 seconds were observed. They

Address for reprint requests: Prof J Marshall, Institute of Neurology, Queen Sq, London WC1N 3BG, UK.

Received 24 March 1983 and in revised form 28 July 1983. Accepted 12 September 1983 occurred daily and were accompanied by slight tremor of the hands and licking of the lips. He was twice incontinent. In May 1968 he had his first generalised convulsion. An EEG was recorded at Runwell Hospital (Drs J Magerison and $C$ Binnie) seven days after the first convulsion and already showed polyphasic but variable complexes. In June 1968 he became dysarthric, ataxic, emotionally labile and no longer grasped instructions properly.

He was transferred to the National Hospital for Nervous Diseases on 11 November 1968 . He was orientated but general knowledge was poor and he could not attempt the 100-7 test. The positive findings were slurred speech, generalised hypotonia, mild choreiform movements and an ataxic gait. The liver was palpable one inch below the costal margin.

The EEG showed periodic complexes; sensory evoked responses (Dr AM Halliday) were $5 \mu \mathrm{V}$ on the right and $9 \mu \mathrm{V}$ on the left. The cerebrospinal fluid contained 2 cells per $\mathrm{cmm}, 0.1 \mathrm{~g} / 1$ protein and a paretic Lange curve. Psychological testing (Dr E Warrington) on the WAIS gave a verbal score of 91 , performance of 62 , and showed evidence of severe generalised dementia. Liver function tests were normal.

On 16 November myoclonic jerks were seen for the first time, more on the right than the left. Because of the enlargement a liver biopsy was performed on 27 November. Professor Sheila Sherlock reported: "There is slight expansion and fibrosis in the portal tracts and hyalinisation of small arterioles and also fibrosis around the large central veins. It is very unusual in one so young. The liver cells appear to be normal and there is no iron deposition or fatty change". Measles virus CFT titre in the serum was 32 , HAI titre 384 , both of which were raised, whereas herpes virus CFT was less than 4 (Professor A Dudgeon). Tests of immunological competence were carried out by Dr GL Asherson who reported: "reaction to phytohaemagglutinin at high concentration was normal but at low concentration was much less than a control subject, suggesting slight depression of the ability of his cells to undergo blast transformation". 


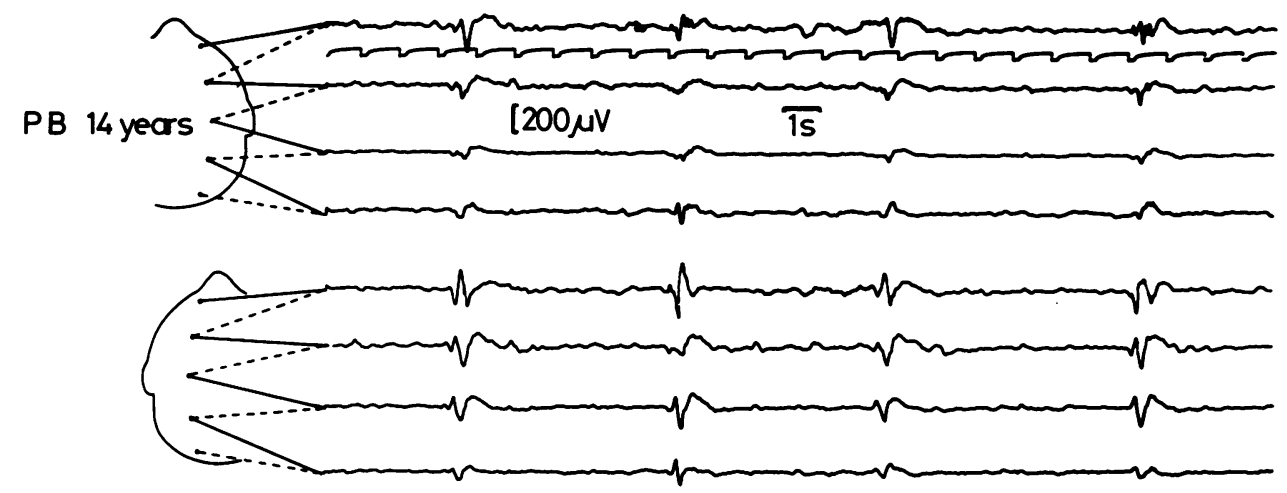

Fig 1 In the first record of 13 November '68 there was still a little alpha rhythm not detectable at this gain, and moderate, mainly frontal, irregular slow activity. Complexes, which occurred at a mean interval of about $6.5 \mathrm{~s}$, were widespread with a maximum in the left central parasagittal area. They were of two types, not necessarily alternating as shown here ( 1 and 3 and 2 and 4 form pairs). The fast component, best seen in Channel 1, is at 9-10 Hz. To save space eight transverse channels of the 16-channel montage have been omitted.

On 7th December involuntary slow flexion of the right upper limb occurring every 5 or 6 seconds began synchronously with EEG discharges. The patient was extremely drowsy and incontinent. He remained thus until January 1969 when he began to improve. The involuntary flexion movements of the limbs continued, causing a peculiar genuflection in his gait every third step and he was occasionally incontinent, but he was out of bed and could attend to his personal needs and answer simple questions.

By September he was at home and attending a day centre. The flexion movements decreased during 1970 and had ceased by February 1971, leaving only slight choreiform movements of the hands and a gait that could best be described as shambling. Generalised convulsions occurred occasionally but otherwise his condition remained unchanged until October 1975 when his mother noted a subtle change. His speech became more slurred, he dropped things more frequently and from being placid and docile became somewhat spiteful. Neurological examination was unchanged. The cerebrospinal fluid contained no cells, $0 \cdot 1 \mathrm{~g} / \mathrm{l}$ protein and a Lange curve 555321100 . The WAIS was verbal 87 , performance 63 . VERs were normal. Measles CFT titre 64, HAI less than 4. IgG 0.018, LgA 0.005 , IgM $0.005 \mathrm{~g} / \mathrm{l}$, all of which were normal; microimmunoelectrophoresis (Professor GT Stevenson) "IgG of restricted mobility in the slow area suggesting most of the IgG represents monoclonal or oligoclonal antibodies".

$\mathrm{He}$ continued to deteriorate slowly and was finally readmitted on 1 July 1981 . At this time he was drowsy and responded to questions with "yes" or "no", not always appropriately. He had difficulty in swallowing, showed continuous choreiform movements and was incontinent. The plantars were flexor on admission but became extensor. Seizures became frequent and later virtually continuous, consisting of tonic elevation of the right upper limb. He continued thus until his death on 23 October 1981.
The electroencephalograms

The EEG was recorded four times at Runwell Hospital (Drs J Margerison and C Binnie) between June and September 1968, and 36 times between November 1968 and August 1981 at the National Hospital.

The record, 7 days after the onset of convulsions, showed complexes more polyphasic and variable than they later became, occurring at long irregular intervals against a background which was not very abnormal and included a prominent responsive alpha rhythm.

When first seen by us, on 13 November ' 68 , the background EEG still showed some ill-defined posterior alpha rhythm and there was continuous irregular moderate voltage frontal slow activity. Complexes occurred with fair regularity at a mean interval of $6.5 \mathrm{~s}$ and had two slightly different wave forms, not necessarily alternating as they do in fig 1 . The first consisted of positive, negative, positive phases, terminating with a long slow negative wave, the whole lasting about $1.5 \mathrm{~s}$; superimposed on it were about half a dozen $9-10 \mathrm{~Hz}$ waves. The second form lacked these faster components and was smaller and more simple than the first which, in the left frontal parasagittal region, reached over $500 \mu \mathrm{V}$. Minor variations on these forms continued throughout subsequent records.

The complexes appeared to be evoked by eye opening or closing and by clangs. Stimuli in various modalities (a train of flashes, a tone burst or an electrical stimulus to the skin) could evoke a complex if delivered about $5 \mathrm{~s}$ after the onset of the last one (Fig 2), the mean spontaneous interval at this time being $6.2 \mathrm{~s}$. Habituation was rapid but could be overcome by adding a second type of stimulus or by substituting it for the first.

In sleep the $10 \mathrm{~Hz}$ component gave place to one at 13$14 \mathrm{~Hz}$, with the same asymmetry, and this rhythm also occurred episodically between complexes, appearing to form sleep spindles. Intravenous methohexitone gave rise 


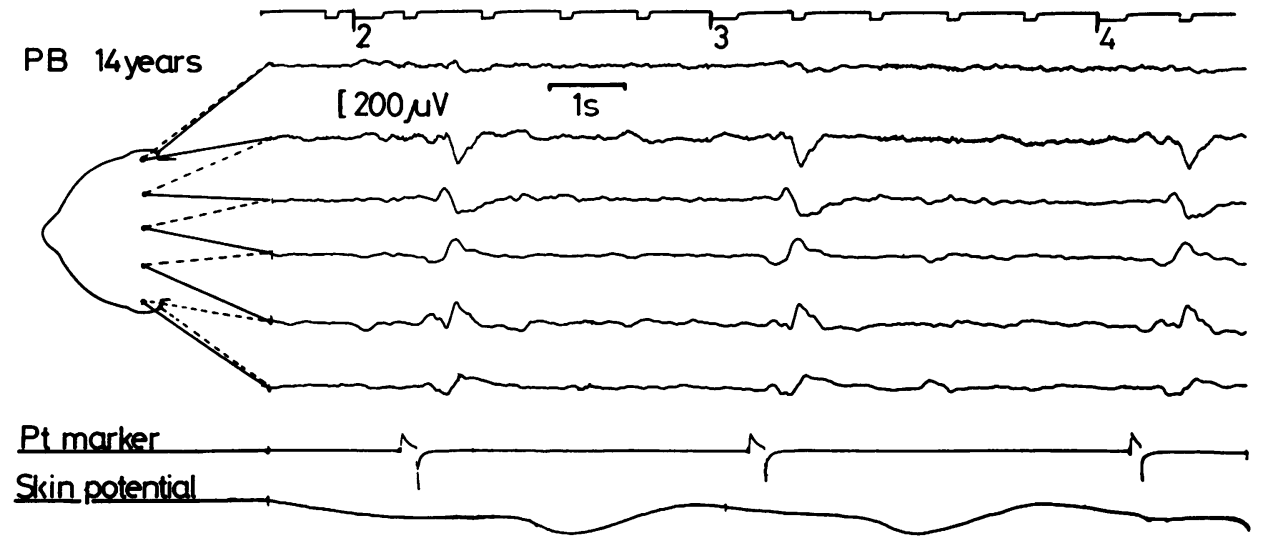

Fig 225 November '68. At this time the mean spontaneous interval between complexes was $6 \mathrm{~s}$. The technician counted aloud at about 5 s intervals (time-mark Channel 1) to which the patient replied by briefty closing a switch; this combination was regularly followed by a complex. Channel 9 shows the change in skin potential about $1 \mathrm{~s}$ after the complex. To save space eight A-P channels of a 16-channel montage have been omitted.

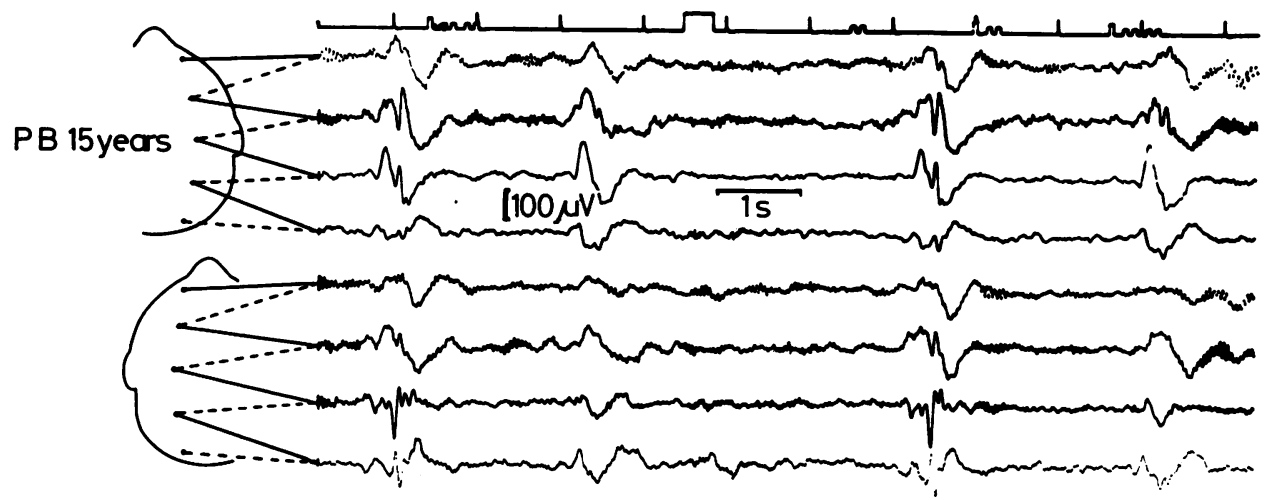

Fig 3 Nearly 13 months after the first record the EEG still shows two distinct forms of complex. It also shows a virtually continuous frontal fast rhythm, which had first been noted nearly a year before and which remained in all except the final records. Eight transverse channels omitted.

to fairly symmetrical $14 \mathrm{~Hz}$ rhythm which, as it subsided, conspicuously followed each complex.

A complex did not interfere with the patient's ability to read or carry out a rhythmic switching task, though there was some suggestion that it disturbed the regularity of counting. It had no effect on the cardiac or respiratory rhythms; on one of the two occasions on which it was recorded the skin potential appeared to change about one sec after each complex (fig 2 ). However, it was not until 13 December ' 68 that any behavioural change was linked to the complex, at which time the patient had regular flexion movements mainly on the right. An EMG of the right forearm flexors showed activity beginning at the same time as the complex, but lasting about $3 \mathrm{~s}$. About this time, when his clinical condition was at its worst, a rhythm at $16-18 \mathrm{~Hz}$ was noted, rather widespread but in later records mainly frontal (fig 3); it persisted as a prominent feature for many years.

During 1969, though his clinical condition was improving, the complexes became more symmetrical and the interval between them shorter until by December it was as little as $2.5 \mathrm{~s}$, with two short periods during which it fell to $1 \cdot 5 \mathrm{~s}$.

In February 1971, when involuntary flexion of the limbs had ceased, complexes persisted with a mean interval of $3.3 \mathrm{~s}$; the faster component, now at about $14 \mathrm{~Hz}$, was best seen in the right temporal region. The general background was one of low to moderate voltage slow waves, together with the prominent frontal fast rhythm. In September 1971, the complexes were absent for the first time and were never seen again; in other respects, however, the record was much the same as before. 


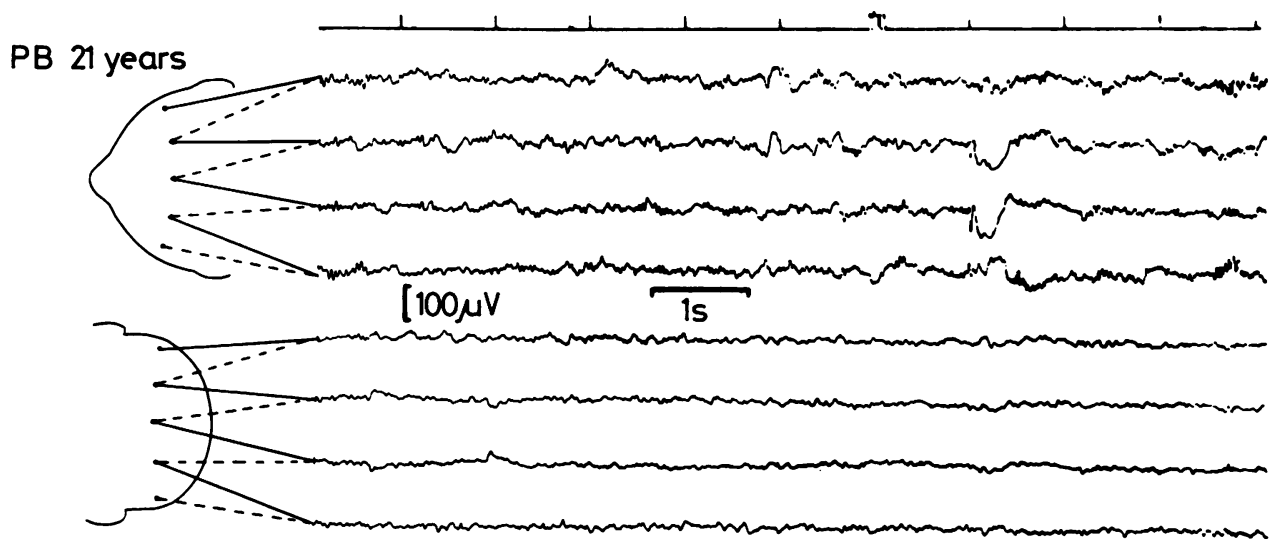

Fig 49 January '76. After the complexes had ceased, some time before September 1971, the EEG looked much as it does here except that on this occasion there are rare left frontal spikes and slow waves, which possibly mark the beginning of a gradual deterioration. Eight A-P channels omitted.

Subsequently there was never any clear improvement in the EEG though at times it seemed that posterior alpha rhythm might be returning. Irregular low voltage slow waves continued anteriorly together with frontal fast rhythm. Deterioration in the EEG seems to have begun at about the beginning of 1976 , clinical change having been noted about October 1975. Random frontal spikes were first noted (fig 4), and a few months later there was a marked increase in frontal slow waves, mainly on the left side.

The last two records, in August 1981, during the terminal phase of his illness, were dominated by a new feature, a nearly continuous, rather rhythmic $1.5 \mathrm{~Hz}$ activity, maximal in the left frontal region. The frontal fast rhythm, which had been so prominent for many years, had disappeared.

\section{Pathological examination}

Postmortem examination showed a very emaciated young male. There was basal bronchopneumonia with pulmonary oedema and bilateral pleural effusions. The brain weighed $1300 \mathrm{~g}$ and showed some shrinkage of the gyri of both frontal poles. After fixation brain slices showed dilatation of lateral and third ventricles and diffuse myelin loss. The corpus callosum was extremely thin and grey. The $U$ fibres appeared surprisingly well preserved in some frontal areas. The deep grey matter was slightly reduced in volume; the optic pathways appeared normal. The substantia nigra appeared extremely pale but the rest of the brainstem, the cerebellum and the spinal cord looked normal.

Blocks taken from many regions of cerebral and cerebellar hemispheres, brainstem and spinal cord were embedded in paraffin. Sections were stained with haematoxylineosin, haematoxylin-van Gieson, Holzer's method for astrocytes, PTAH, Glees and Marsland's silver impregnation, Luxol-fast-blue-cresyl violet and Congo red. Fragments from the substantia nigra were also processed for electron microscopy.

Histological examination showed slightly thickened lep- tomeninges with occasional clusters of lymphocytes. The blood vessels were normal. In the cerebral cortex there was a variable amount of nerve cell loss but the total number of cells was increased because of astrocytic and microglial proliferation without lymphocytes and plasma cells. In the deeper layers of the cortex and at the level of the $U$ fibres the cellularity was further increased and included rod cells and gemistocytic astrocytes. Occasional cortical neurons showed neurofibrillary changes that appeared faintly argyrophilic and strongly Congo red positive and birefringent. The white matter showed a diffuse severe loss of myelin with a moderate decrease of density of axons and an increased number of astrocytes. Fat laden macrophages and inflammatory cells were not prominent. Of the deep grey nuclei, the thalamus showed the most severe loss of nerve cells while striatum and pallidum were only moderately affected. The pyramidal layer of the hippocampus contained several microglial nodules and the lateral geniculate body showed a severe loss of nerve cells.

In the midbrain there was slight gliosis and occasional microglial nodules were present in the quadrigeminal plate, as well as a few tangles in the aqueductal grey matter and nuclei of the raphe. The substantia nigra showed neuroglial nodules (fig 5) and perivascular cuffing. Very few pigmented nerve cells were seen and some of them contained neurofibrillary tangles (fig 6a). Numerous microglial nodules and inflammatory cells were also seen in both the tegmentum and pes of the pons and in the inferior olives. In the locus coeruleus occasional cells contained Lewy's bodies.

No abnormalities were seen in the cerebellum or in the spinal cord except a very occasional microglial nodule in the dentate nuclei and in the anterior horns at lumbar level. Inclusion bodies were not observed.

Electron microscopy of the midbrain showed poor preservation of all structures with the exception of twisted tubules that were extremely well preserved. These corresponded to the tangles seen with light microscopy and were arranged in bundles that filled the cell bodies almost com- 


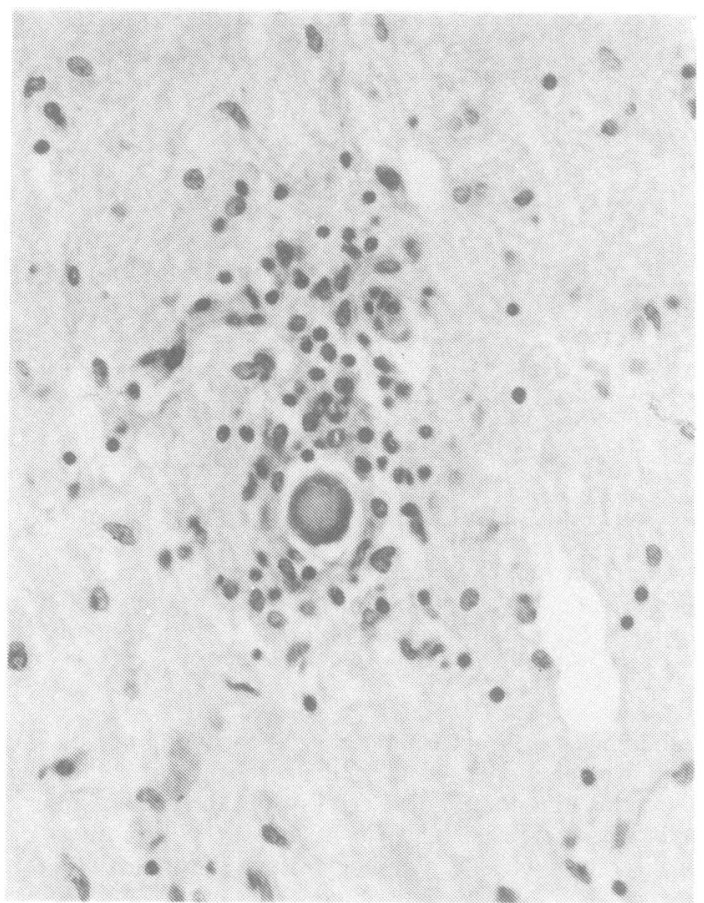

Fig 5 Section of the midbrain showing a necrotic nerve cell in the substantia nigra surrounded by microglial cells (Haematoxylin and eosin $\times 280$ ). pletely (fig 6b). Most of the tubules showed regular constrictions at $700 \mathrm{~nm}$ distance and a maximum thickness of about $200 \mathrm{~nm}$ and of $100-110 \mathrm{~nm}$ in the region of the twists.

In summary, pathological findings showed a subacute encephalitic process involving the white more than the grey matter and the cerebral hemispheres as well as the brainstem. In the hemispheres the white matter showed extensive demyelination; gliosis was also diffuse and extended to the deeper layers of the cortex, the thalamus and, to a lesser extent, the striatum. The lesions supported the clinical and electroencephalographic diagnosis of SSPE which, in the brainstem, was still in an active phase.

\section{Discussion}

The illness in this patient began in a classical manner with deterioration in school performance, soon to be followed by fits. Its evolution over nine months to the point at which it seemed he would not long survive was likewise typical. The relatively abrupt improvement was not associated with any specific therapy. It continued until he attained a satisfactory functional status, though short of his premorbid level. Physically he was intact but his intellectual capacity remained limited and he continued to have fits. He remained thus for almost seven years when relapse was heralded by subtle change in behaviour. The illness thereafter progressed relentlessly with

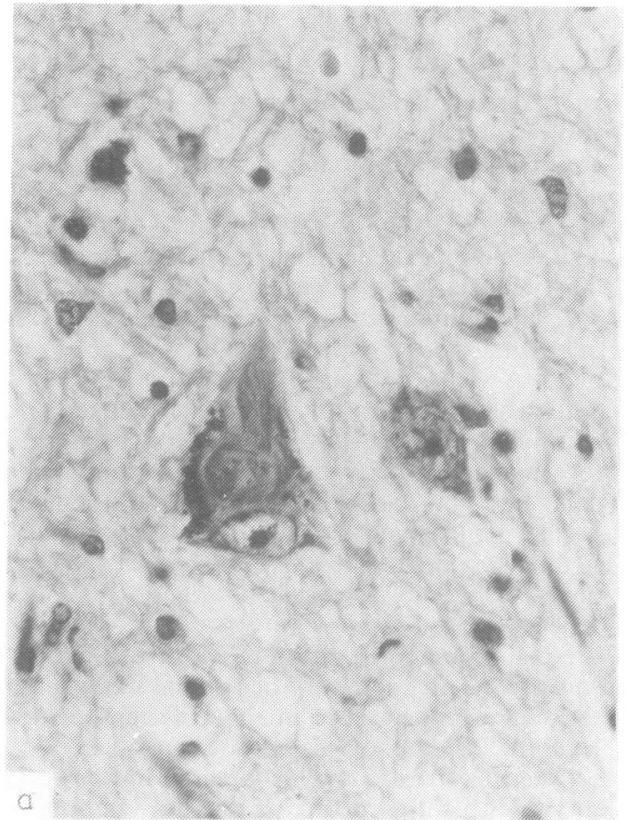

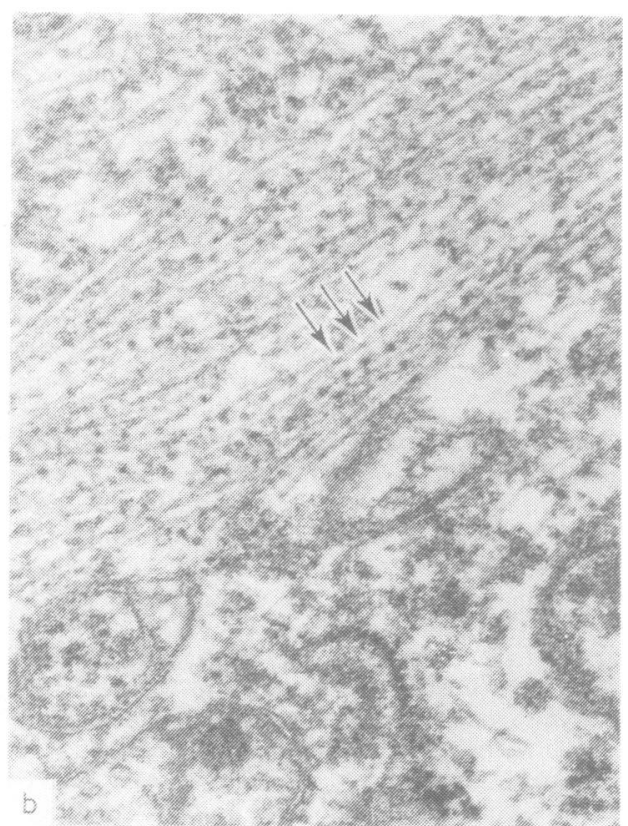

Fig 6 (a) In the substantia nigra a few residual nerve cells contain neurofibrillary tangles that displace both the nucleus and the pigment (Haematoxylin and eosin $\times 630$ ). (b) An electronmicrograph shov's bundles of tubules some of which show periodical constriction (arrows) $\times 85000$. 
deteriorating mental function and increasing frequency of fits over a further six years to his death.

The only unusual clinical feature (apart from the remission and long survival) was the hepatic enlargement in the early stages. Jaundice before SSPE has been described. ${ }^{24}{ }^{25}$ In one series of ten cases five showed evidence of previous liver disease, three having had clinical hepatitis. ${ }^{26}$ In the present case there was no history of hepatitis, but the liver was enlarged, and though there was no evidence of cellular damage, there were unusual histological changes.

The EEGs of the great majority of cases of SSPE conform remarkably to the well known stereotype. It is rare for the complex to persist for nearly 3 years, if only because the victim is usually dead long before this time. In most cases the complexes undergo change with time (and with the state of alertness) but in a given record the main components are virtually constant, though minor changes in relative amplitude of these components cause departures from the stereotyped form; often the constancy is more obvious in some channels than in others, suggesting that the basic form is constant and that it is the mode of spread that has changed.

The present case was different in that it was possible to define two wave forms in the same record, apparently mixed in random fashion and not obviously related to the course of the illness or the patient's state at the time. We have seen this phenomenon before and it is possible that more careful analysis of wave form would show it more often. In the present case the differences appeared to lie mainly in a relatively large or small amplitude of the faster component. In a previous case the initial components were always the same but were sometimes followed by two larger slower waves; two such long complexes never occurred together, being separated by one to four short complexes, never more. Thus one form of complex clearly affected the probability of the other, for which there was no evidence in the present case.

Various factors indicate a relationship between the complexes and the alerting and sleep mechanisms. The evocation by stimuli was first described by Pampliglione and Martin, ${ }^{27}$ and has been frequently noted since, though it is the exception rather than the rule; a "refractory period" can usually be demonstrated, in this case about $5 \mathrm{~s}$. Changes in the periodicity, regularity and wave form in sleep are usual, though not predictable. More interesting was the change in the fast component of the complex from about $9-10 \mathrm{~Hz}$ to $14 \mathrm{~Hz}$ and the great similarity in frequency and distribution between the latter and the sleep spindles which occurred at random or immediately following the complexes. Similarly, after the general effects of Brietal had subsided a burst of $14 \mathrm{~Hz}$ rhythm followed each complex; this, of course, might have been because the Brietal narcosis had given place to natural sleep.

Whether or not these effects of stimulation and of sleep were in any way specific is doubtful since comparable effects are not rare in other conditions, notably the evocation of paroxysmal discharges, such as "temporal lobe spikes", by sleep and of myoclonus with associated EEG changes by stimuli.

An asymmetry of the complexes was constant in the early stages of the disease. Although recordable everywhere the amplitude of the slow components was greatest in the left frontal region while those of the $10 \mathrm{~Hz}$ component, its $14 \mathrm{~Hz}$ counterpart in sleep and the sleep spindles themselves were larger on the right, perhaps suggesting that this was the more normal side. This distribution changed in the later records, with the maximum shifting to the right temporal region, but the terminal slow activity was again mainly left frontal. Some asymmetry of the complexes is common and can be much more than in this case, but is not usually accompanied by a corresponding asymmetry of the clinical signs, specifically of the myoclonus. If there is clinical asymmetry it is more likely to be reflected in the background slow activity than in the complexes.

Correlation between the complexes and the clinical state was poor. Though clinical improvement began in January 1969 and periodic involuntary movements declined and were absent by February 1971 complexes persisted and did not disappear until September 1971. They did not recur when the patient relapsed though the abnormal Lange curve as well as the clinical change indicated renewed activity of the disease.

A number of histological features deserve comment. The absence, in our case, of inclusion bodies does not militate against the diagnosis in the face of so typical a clinical picture. Cases of SSPE without inclusions have been recorded. ${ }^{28-31}$ Neurofibrillary changes of the Alzheimer type have previously been observed, the first report being by Malamud et al. ${ }^{1}$ Tangles in our patient consisted ultrastructurally of masses of twisted tubules $200 \mathrm{~nm}$ wide and with constrictions at about $700 \mathrm{~nm}$ distance. The appearances were similar to those of the twisted tubules found in Alzheimer's disease. Mandybur et al ${ }^{32}$ insist on the non-specificity of these findings for they can be present in degenerative, toxic and infectious processes. In the majority of cases they are associated with long survival. However, they have been described in three patients who survived no longer than 12 months. ${ }^{4334}$

The finding of occasional Lewy bodies in pigmented cells of the locus coeruleus is surprising and 
its significance is unclear. Lewy bodies are a common feature in idiopathic Parkinsonism; the only report of Lewy bodies other than in Parkinsonism we can find is that by Agamanolis and Greenstein ${ }^{35}$ who found them in the pigmented nuclei in a case of ataxia-telangiectasia.

Recorded cases of SSPE with survival longer than 5 years are infrequent and have been recently reviewed by Dumas et al. ${ }^{18}$ One of us (WAC) has personal experience of four other cases of long survival, three of which have been previously reported. ${ }^{1036}$ Survival ranged from 6 to 14 years but necropsy was not performed.

The evolution of the present case can best be explained in terms of a phasic illness affecting different sites. The initial illness, which was associated with EEG complexes, was the result of diffuse involvement of the cerebral hemispheres. It was contained by the immune mechanisms of the brain leading to clinical improvement and later to disappearance of the complexes. Ultimately containment failed and a second wave of the disease mainly affecting the brainstem led to clinical deterioration and death. The histological findings are in accord, there being extensive demyelination and diffuse gliosis in the cerebral hemispheres, with evidence in the brainstem of more active disease.

\section{References}

' Malamud N, Haymaker W, Pinkerton $\mathrm{H}$. Inclusion encephalitis with a clinicopathologic report of three cases. Am J Pathol 1950;26:133-53.

${ }^{2}$ Eicke WJ, Ziegler W. Ein Beitrag zue Frage der atypischen Encephalitis. Nervenartz 1950;21:312-8.

${ }^{3}$ Kurtzke JF. Inclusive body encephalitis a non fatal case. Neurology (Minneap) 1956;6:371-6.

${ }^{4}$ Krucke W. Uber eine besondere Form der spontanen Encephalitis. Nervenartz 1957;28:289-301.

${ }^{5}$ Landau WM, Luse SA. Relapsing inclusion encephalitis (Dawson type) of eight years duration. Neurology (Minneap) 1958;8:669-76.

${ }^{6}$ Lebascle J. Leucoencéphalite sclérosante subaique d'évolution prolongée. Sem Hôp (Paris) 1961;37:1341-6.

${ }^{7}$ Osetowska E. In: Encephalitides, Proceedings of a Symposium, Antwerp 1959. van Bogaert L, Radermecker J, Hozay J, Lowenthal A, eds. Amsterdam, Elsevier, 1961:414-69.

${ }^{8}$ Osetowska E, Torck P. Subacute sclerosing leucoencephalitis. World Neurol 1962;3:566-79.

${ }^{9}$ Pearce JMS, Barwick DD. Recovery from presumed subacute inclusion-body encephalitis. $\mathrm{Br} \mathrm{Med} J$ 1964;2:611-3.

${ }^{10}$ Cobb WA, Morgan-Hughes JA. Non fatal subacute sclerosing leucoencephalitis. J Neurol Neurosurg Psychiatry 1968;31:115-23.

${ }^{11}$ Kennedy C. A ten year experience with subacute sclerosing panencephalitis. Neurology (Minneap) 1968,18:58-9.

${ }^{12}$ Resnick JS, Engel WK, Sever JL. Subacute sclerosing panencephalitis: spontaneous improvement in a patient with elevated measles antibody in blood and spinal fluid. New Engl J Med 1968;279:126-9.

13 Jabbour JT, Garcia JH, Lemmi H, Ragland J, Duenas DA, Sever JL. Subacute sclerosing panencephalitis. A multidisciplinary study of eight cases. JAMA 1969;207:2248-54.

${ }^{14}$ Donner M, Waltimo O, Porras J, Forsius H, Saukkonen A-L. Subacute sclerosing panencephalitis as a cause of chronic dementia and relapsing brain disorder. $J$ Neurol Neurosurg Psychiatry 1972;35:180-5.

${ }^{15}$ Dubois-Dalc M, Coblentz JM, Pleet AB. Subacute sclerosing panencephalitis. Unusual nuclear inclusions and lengthy clinical course. Arch Neurol 1974;31:355-63.

${ }^{16}$ Procopis PG. Subacute sclerosing panencephalitis a study of 25 patients. Proc Austral Assoc Neurol 1974;11:133-5.

${ }^{17}$ Mirimanoff P. La dystrophie spongieuse hereditaire des enfants (Canavan: Van Bogaert-Besbrand). J Neurol Sci 1976;28:159-85.

${ }^{18}$ Dumas M, Girard PL, Gray F, Escourolle R. Rémission clinique et électroencéphalographique prolongée et totale puis décès au cours d'une panencéphalite sclérosante subaiguë. Rev Neurol (Paris) 1980;136:165-183.

${ }^{19}$ Bellman MH, Dick G. Register of cases of subacute sclerosing panencephalitis. Br Med J 1977;1:430-1.

${ }^{20}$ Haddad FS, Risk WS, Jabbour JT. Subacute sclerosing panencephalitis in the Middle East: Report of 99 cases. Ann Neurol 1977;1:211-7.

${ }^{21}$ Enders-Ruckle G. Frequency, serodiagnosis and epidemiological features of subacute sclerosing panencephalitis (SSPE) and epidemiology and vaccination policy for measles in the Federal Republic of Germany (FRG). Dev Biol Stand 1978;41:195-207.

${ }^{22}$ Risk WS, Haddad FS, Chemali R. Substantial spontaneous long-term improvement in subacute sclerosing encephalitis. Arch Neurol 1978;35:494-502.

${ }^{23}$ Risk WS, Haddad FS. The variable natural history of subacute sclerosing panencephalitis. Arch Neurol 1979;36:610-4.

${ }^{24}$ Thiry S. Réunion d'étude neurologique. Rev med Liege 1956;11:223-4.

${ }^{25}$ Brocher JM, Dechef G. Etude anatomo-clinique d'un cas de leucoencéphalite sclerosante subaiguë. Acta Neurol Psychiat Belg 1957;10:775-91.

${ }^{26}$ Simpson JA. Subacute inclusion body encephalitis. A possible association with infective hepatitis. Lancet 1961;2:685-7.

${ }^{27}$ Pampiglione G, Martin F. Periodicité de quelques phénomènes cérébraux (Etude electroencéphalographique). Schweiz Arch Neurol $U$. Psychiat 1953;71:277-84.

${ }^{28}$ Schiott CR. On the significance of inclusion bodies in subacute encephalitis. In: Encephalitides, Proceedings of a Symposium, Antwerp 1959. Ed. L. van Bogaert, J Radermecker, J. Hozay, A. Lowenthal. Amsterdam, Elsevier, 1961:410-13. 
${ }^{29}$ Gutewa J, Osetowska E. A chronic form of subacute sclerosing encephalitis (a case with a history of 5 years). Clinical and pathological study. In: Encephalitides, Proceedings of a Symposium, Antwerp 1959. von Bogaert L, Radermecker J, Hozay J, Lowenthal A. eds. Amsterdam, Elseivier, 1961:384-404.

${ }^{30}$ Himmelhoch J, Pincus J, Tucker G, Detre T. Sub-acute encephalitis: behavioural and neurological aspects. $\mathrm{Br}$ J Psychiatry 1970;116:531-8.

${ }^{31}$ Zeman W. Subacute sclerosing panencephalitis and paramyxovirus infections. In: Handbook of Clinical Neurology. Vinken PJ, Bruyn GW, eds. Vol. 34 Infections of the Nervous System. Amsterdam: North Holland Publishing Co. 1978:343-68.

${ }^{32}$ Mandybur TI, Nagpaul AS, Pappas Z, Niklowitz WJ.
Alzheimer neurofibrillary change in subacute sclerosing panencephalitis. Ann Neurol 1977;1:103-7.

${ }^{33}$ Corsellis JAN. Subacute sclerosing leucoencephalitis: a clinical and pathologic report of two cases. J Ment Sci 1951;97:570-83.

${ }^{34}$ Bornstein B, Sandbank U, Tamir M, Breham J. Subacute sclerosing leukoencephalitis with fulminating evolution. Rev Neurol (Paris) 1961;105:430-42.

${ }^{35}$ Agamanalis DP, Greenstein JI. Ataxia-telangiectasia. Report of a case with Lewy bodies and vacuolar abnormalities within cerebral tissue. J Neuropath Exper Neurol 1979;38:475-89.

${ }^{36}$ Cobb WA. The periodic events of subacute sclerosing leucoencephalitis. Electroencephalogy Clin Neurophysiol 1966;21:278-94. 